\title{
A Simple Nonmydriatic Self-Retinal Imaging Procedure Using a Kowa Genesis-D Hand-Held Digital Fundus Camera
}

\author{
Ugur Ozerdem
}

La Jolla Bioengineering Institute, La Jolla, Calif., USA

\section{Key Words}

Central nervous system • Fundus · Retina · Self-imaging •

Artery $\cdot$ Vein $\cdot$ Head-down tilt $\cdot$ Microgravity

\begin{abstract}
Research on vascular adaptation to microgravity in the central nervous system requires a simple, noninvasive, direct imaging technique that can be performed with compact equipment. In this report we describe a practical, nonmydriatic, retinal self-imaging technique using a Kowa Genesis-D hand-held digital camera and a Black and Decker laser level. This simple technique will be useful to clinical physiologists conducting microgravity research, as well as for the studies of high-altitude medicine and aviation physiology.
\end{abstract}

Copyright $\odot 2009$ S. Karger AG, Basel

\section{Introduction}

Evaluating microgravity-induced vascular changes in the central nervous system during spaceflight or during simulated microgravity research is hampered by the inability to view structures directly due to the barrier posed by the skull bones [1]. However, the retina (an outgrowth of the brain) as well as its vessels and optic nerve are visible directly through the pupil of the eye, and can be imaged with any digital fundus camera $[2,3]$.

\section{KARGER}

Fax +4161306 1234 E-Mail karger@karger.ch www.karger.com (c) 2009 S. Karger AG, Basel

0030-3747/09/0423-0125\$26.00/0

Accessible online at:

www.karger.com/ore
Blood and tissue fluid shifts associated with weightlessness offer unique opportunities to study perturbations in vascular transmural pressure changes and associated edema in the upper body (face, eyelids, vocal cords, brain) during space explorations. In a microgravity (or simulated microgravity) environment capillary pressure (Pc) increases in the head and neck. The reason for the increase of $\mathrm{Pc}$ in the upper body is because hydrostatic fluid pressure within the vasculature behaves like a vertical column of water and is affected by gravity. The difference between Pc and interstitial fluid pressure is greater in magnitude in the upper body parts during space flight $[4,5]$. An increase in Pc in the upper body counteracts interstitial fluid pressure and therefore increases net transcapillary fluid leakage and edema.

High-resolution, hand-held digital fundus cameras have recently become available for retinal imaging. Kowa Genesis-D is a compact, lightweight, hand-held fundus camera. This system is equipped with a built-in digital camera which provides 2.0 million pixels of resolution and an LCD monitor screen. In this brief report we describe a simple, noninvasive technique for retinal self-imaging that can be used in clinical physiology to evaluate the adaptive changes in retinal vasculature (central nervous system vasculature) in microgravity. 


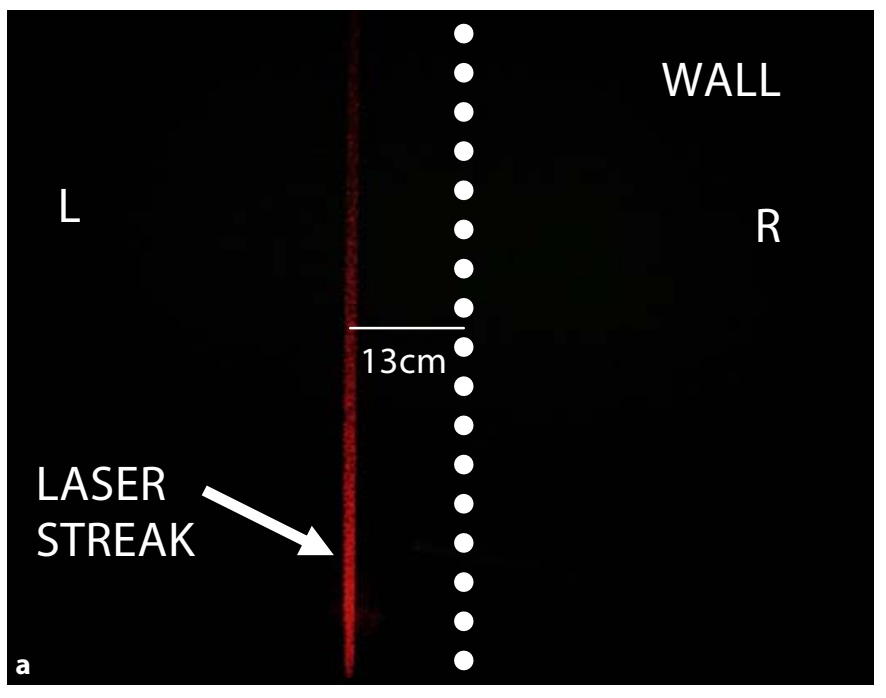

Fig. 1. a The laser streak of Black and Decker, DL220S, level was projected onto a wall in a dark room $100 \mathrm{~cm}$ away from the right eye, $13 \mathrm{~cm}$ medial (nasal) to the optical axis, represented by the perpendicular dashed line drawn from the triangular notch at the top of the picture frame. A $13-\mathrm{cm}$ nasal displacement of the laser

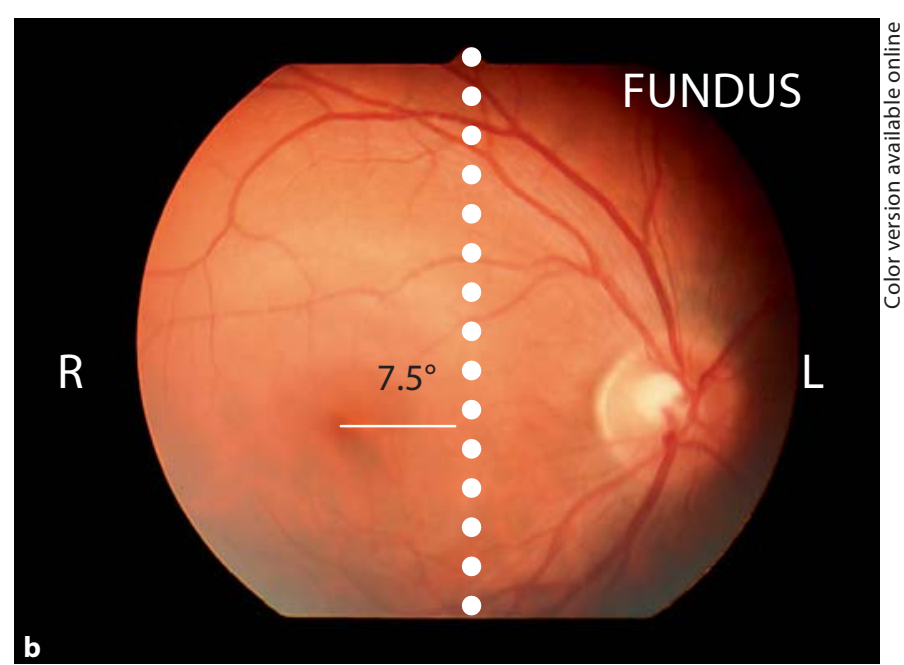

streak on the dark wall from the optical axis at $100 \mathrm{~cm}$ corresponds to approximately $7.5^{\circ}$ of temporal displacement of the macula from the optical axis in the fundus photograph seen in $\mathbf{b}$. b Optic nerve head, major vessel and macula in a single photographic frame are shown.

\section{Materials, Methods and Results}

A Kowa Genesis-D fundus camera (serial No. 1501500288, Tokyo, Japan) was used as a hand-held digital fundus camera. The weight of the camera is $1,070 \mathrm{~g}$ and the dimensions are $74.5 \mathrm{~mm}$ (width) $\times 197 \mathrm{~mm}$ (depth) $\times 278.5 \mathrm{~mm}$ (height). This camera has approximately $30^{\circ}$ of horizontal angle of view. Since the angular distance between fovea and optic nerve is approximately $15^{\circ}$ [6], a $7.5^{\circ}$ adduction of the eye was calculated to translate to a $7.5^{\circ}$ temporal displacement of the macula off the optical axis. A simple laser level (Black and Decker, DL220S, Towson, Md., USA) was used for aligning the eye $7.5^{\circ}$ nasally (adduction) so that both optic nerve head and macula were approximately located in the center of the digital image frame obtained with this camera. The laser streak was projected onto a wall in a darkroom $100 \mathrm{~cm}$ away from the right eye. The wall was viewed through the objective lens of the camera which functioned as an ocular eyepiece for this imaging technique. The eyes were dark-adapted for $5 \mathrm{~min}$ in the dark room. The forehead rest of the camera was placed on the frontal bone. The original eyepiece of the camera served as an objective lens to view the laser streak on the wall (fig. 1a). The laser streak was then shifted on the wall to project $13 \mathrm{~cm}$ off the optical axis, which was represented by the triangular notch of the picture frame in this particular camera. The $13-\mathrm{cm}$ horizontal displacement of laser streak was calculated by using basic trigonometry $\left(100 \mathrm{~cm} \times \tan 7.5^{\circ}=13 \mathrm{~cm}\right)$. The right eye then gazed at the laser streak on the wall while the camera position on the forehead was kept constant. The shutter on the camera handle was switched on by using the right thumb to capture the image (fig. 1b). The entire procedure, including $5 \mathrm{~min}$ of the dark adaptation period, took less than $7 \mathrm{~min}$. The JPEG image obtained was of sufficient qual-

ity to apply NIH image J 1.39t image analysis software to quantify the relative size of major vascular structures (retinal arteries and veins) representative of central nervous system vasculature. A practical application of this technique in a simulated microgravity model with $6^{\circ}$ head-down tilt is shown in figure 2 .

\section{Discussion}

In the late 1970s, Kowa RC-2 cameras were modified successfully by the addition of custom-made bite plates to position the camera, attaching cross-hair targets, and a focusing light in the view finder (ocular eyepiece) [7]. Our technique uses a more advanced camera which requires only a miniature external laser level (Black and Decker, DL220S), and no modifications to the camera hardware. This easy-to-apply, nonmydriatic procedure can be used by crew members without any compromising vision or sacrificing safety in situations where payload and imaging time are limited (such as spacecraft, aircraft, and tent of a mountaineer physiologist). The compactness of this hand-held fundus camera coupled with the simplicity of the procedure we describe makes it possible for anyone who can use a standard digital camera to perform retinal self-imaging in a darkroom with a wall in $100 \mathrm{~cm}$ distance. Therefore, changes in central nervous system (ret- 
Fig. 2. A practical application of the selfretinal vascular imaging technique in $\mathrm{mi}$ crogravity research. a The same image as in figure $1 \mathrm{~b}$ was compared with the selffundus photograph obtained during bedrest, after $45 \mathrm{~min}$ of supine bedrest with $6^{\circ}$ of head-down tilt. Caliber of the superior temporal retinal artery (stra) and superior temporal retinal vein (strv) in the same anatomic location (arrows) was measured with NIH image J 1.39t image analysis software in pixels. The measurement reveals a wall diameter of 25,554 and 29,120 pixels for stra and strv, respectively, in standing position. b Following $45 \mathrm{~min}$ of supine bedrest with $6^{\circ}$ of head-down tilt (HDT) a reduction of vascular caliber to 24,498 and 27,893 pixels was noted for stra and strv, respectively.
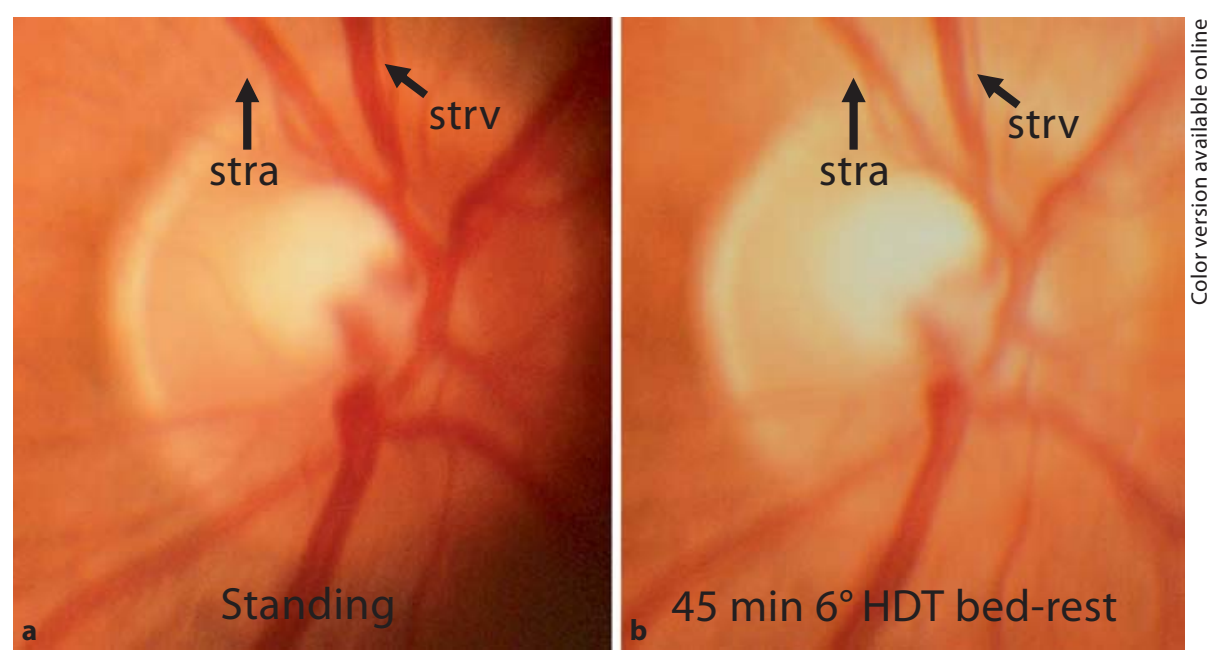

inal) vasculature can be monitored in locations where it is not feasible to use a conventional retinal camera, and without the expertise of a specialist/ophthalmologist. Oral fluorescein angiography [8] can be accomplished with simply taping excitation and emission filters (Roscolux transparent filters, Rosco Laboratories Inc., Stamford, Conn., USA) in the light pathway of the projecting prism and objective lens, respectively, in this camera.

The neurosensory retina is an embryological derivative of the diencephalon, and is thus part of the central nervous system, as is the optic nerve. The retinal artery is a branch of ophthalmic artery, which is the first branch of internal carotid artery. Using the simple, retinal selfimaging procedure and equipment described herein, we expect that changes in central nervous system vessels can be studied more extensively thereby contributing significantly to the fields of microgravity research, aviation physiology and in high-altitude medicine.

\section{Acknowledgments}

We are grateful to US Department of Defense-CDMRP (BC084220), NIH-Eunice Kennedy Shriver National Institute of Child Health and Human Development (R21-HD052126), NIHNational Institute of Biomedical Imaging and Bioengineering (R03EB006746), and University of California, Tobacco-Related Disease Research Program (TRDRP 16IT-0212) for their support of our research. This brief report is dedicated to a stellar clinicianscientist and an outstanding mentor, Dr. William R. Freeman, who has contributed vastly to vitreoretinal imaging, and surgery fields.

\section{References}

1 Ueno T, Ballard RE, Macias BR, Yost WT, Hargens AR: Cranial diameter pulsations measured by non-invasive ultrasound decrease with tilt. Aviat Space Environ Med 2003;74:882-885.

2 Miller N, Drachman DA: The optic nerve: a window into diseases of the brain? Neurology 2006;67:1742-1743.

3 Msall ME: The retina as a window to the brain in vulnerable neonates. Pediatrics 2006;117:2287-2289.
4 Watenpaugh DE, Hargens AR: The cardiovascular system in microgravity; in Fregly MJ, Blatteis CM (eds): Handbook of Physiology: Enviromental Physiology. New York, Oxford University Press, 1996, pp 631-674.

5 Parazynski SE, Hargens AR, Tucker B, Aratow M, Styf J, Crenshaw A: Transcapillary fluid shifts in tissues of the head and neck during and after simulated microgravity. J Appl Physiol 1991;71:2469-2475.
6 Rohrschneider K: Determination of the location of the fovea on the fundus. Invest Ophthalmol Vis Sci 2004;45:3257-3258.

7 Philpott DE, Bailey PF, Harrison G, Turnbill C: Modification of a Kowa RC-2 fundus camera for self-photography without the use of mydriatics. Brain Res Bull 1979;4:123-125.

8 Watson AP, Rosen ES: Oral fluorescein angiography: reassessment of its relative safety and evaluation of optimum conditions with use of capsules. Br J Ophthalmol 1990;74: $458-461$. 